\title{
Changes in colour contrast sensitivity associated with operating argon lasers
}

\author{
KEMAL GÜNDÜZ* AND GEOFFREY B ARDEN
}

From the Department of Clinical Ophthalmology, Institute of Ophthalmology, Judd Street, London, and Electrodiagnostic Clinic, Moorfields Eye Hospital, London

SUMmARY A new test of colour vision using computer graphics has been used to obtain quantitative estimates of colour contrast sensitivity in ophthalmologists before and after they have treated patients by argon laser retinal photocoagulation. The colour vision of all subjects is normal when tested with the 100-hue test and HRR (Hardy, Rittler, Rand) plates, but colour contrast sensitivity measured along a tritan colour confusion line is selectively impaired after a treatment session. No such change occurs after a medical session spent examining patients with a fundus camera. In younger ophthalmologists the sensitivity recovers several hours after the treatment session ends, but in some persons there is a prolonged and possibly permanent elevation of threshold.

In the last decade the use of lasers in ophthalmology has provided some of the most important advances in the treatment of disease. The long-term beneficial effects (especially panretinal photocoagulation in diabetes) of laser therapy $y^{1-3}$ are undoubted, but there is still some concern about the side effects of the treatment itself. It has been shown that panretinal photocoagulation causes short-term losses in visual acuity and a temporary loss of foveal contrast sensitivity, as well as longer-term side effects. ${ }^{3.6}$

In addition there is of course concern about the safety of the users of medical lasers. Filters automatically protect the ophthalmologist's eye when the viewing beam changes to the coagulating beam. Even so, when the low-power aiming beam is operating, brilliant reflections ('flashbacks') from the plane surface of the contact lens may enter the eye. There have been numerous investigations into the threshold for laser damage to the retina. Any momentary irradiance in the pupil plane exceeding $2.5 \mathrm{~mW} / \mathrm{cm}^{2}$ is considered to be dangerous for bystanders, and this level is found to the side of the contact lens or within $1 \mathrm{~m}$ of its front surface. ${ }^{7}$ It has been shown that even additive effects of several flashbacks plus the treatment beam (which is considered very safe even for

*Present address: Gazi Mustafa Kemal Bulvari, 116/3, Maltepe 06570, Ankara, Turkey.

Correspondence to Professor G B Arden, Institute of Ophthalmology, Judd Street, London WC1H 9QS. hours of viewing) never exceeds the limit of $10 \mathrm{~mJ} /$ $\mathrm{cm}^{2}$ per day. ${ }^{8}$

We have devised a new method of testing colour vision using a personal computer to drive a colour graphics peripheral and a colour television monitor. The test is an extension of contrast sensitivity testing ${ }^{9}$ to the domain of colour. In monochromatic contrast sensitivity tests a grating is presented to the patient, and the minimum degree of luminance contrast which is visible is determined. The computer in this new test calculates the voltages which must be presented to the monitor to produce a grating in which luminance is constant, but in which the colour varies across the screen. ${ }^{10}$ The minimum detectable colour contrast is determined. Loss of luminance contrast sensitivity to low spatial frequencies is a very sensitive indicator of visual defects in a variety of neuro-ophthalmological conditions, and losses precede those detectable with ordinary sight test charts. In the same way it appears from our results that colour contrast sensitivity is a method of detecting losses of colour vision when other tests may fail. ${ }^{60-12}$ Thus the minimal degree of protanomaly which can be detected by HRR plates corresponds to a colour contrast threshold which is over $300 \%$ of the average normal mean value, and $250 \%$ of the maximum normal threshold.

Some of the reasons for the success of the method are that the grating is presented in the centre of a large uniform field, so that when it is below threshold 
it is indistinguishable from the field. Thus edge effects and variations of illumination cannot affect the result. The grating also appears in brief flasheswhich occupy only 2 TV frames -4 times a second. Thus the test incorporates spatiotemporal factors, which are important in the successful use of luminance contrast gratings ${ }^{13}$ and also for the discrimination of colour. ${ }^{14}$ Again, the patient's relative spectral sensitivity is determined on the same TV system by heterochromatic flicker photometry before colour vision is tested, so that as far as possible the test colours are accurately isoluminant for each subject: because of differences between individuals, no other test of hue discrimination can rule out clues based on luminance differences. Finally, the test is automated; threshold is repeatedly determined, and the variance of the measurements calculated by the computer, until a reliable result is obtained.

In producing the test we have calibrated it by determining the thresholds of a number of normal people, most of whom are workers in the hospital. In the course of this we retested a number of the volunteers to discover the short- and long-term reproducibility of the values of threshold. We discovered that some doctors' results showed a considerably greater variability than was the case with most persons, and further investigation showed that this variability was associated with the use of medical lasers. Therefore we specifically measured colour thresholds in doctors before and after they had spent a session using the argon laser. The results indicate that laser usage is associated with a loss of colour contrast sensitivity. Despite the fact that this phenomenon is in most cases temporary, this appeared to us sufficiently important to warrant a preliminary report on a small series.

\section{Subjects and methods}

\section{EQUIPMENT}

The system consists of a Nimbus microcomputer (Research Machines, Oxford), which drives a Pluto 1 colour graphics system. The latter produces images on an RGB (red, green, blue) colour monitor (Electronic Visuals 5000). The Pluto 1 can display a palette of 256 colours chosen from over 17 million, and the program arranges these to be isoluminant within $1 \%$. The colours are all specified in terms of the CIE* (XYZ) fundamentals. They are used to colour 2 cycles of a square wave grating subtending $0.6 \mathrm{c} /$ degree, which occupies the central $25 \%$ of the monitor screen. The surround has the hue of the central colour of the palette. In general the range of hues displayed falls on either a protan, deutan, or tritan colour confusion line ('axis'). There is no *Commission Internationale d'Eclairage. generally agreed definition of colour contrast. We have used an operational definition: colour contrast is defined as 0 when all parts of the grating have the same colour, and as $100 \%$ when the difference between the colours is the maximum possible with the system. The CIE co-ordinates of these colours are determined by the emissions of the three phosphors.

The colour contrast threshold is measured by displaying a grating in which colour contrast is 0 , and gradually incrementing the colour contrast in steps of $1 \%$ every second (method of ascending limits). In our standard protocol the grating appears 4 times a second with a duty cycle of $20 \%$, that is, for a nominal $50 \mathrm{~ms}$ : during this period the area of the grating is twice briefly excited by the TV raster. The subject sees a grating which repeatedly appears and vanishes: it appears to flash on and off. At threshold neither the colours nor the outlines are distinct; there is only the impression that 'something' is appearing. The incrementation of contrast which occurs every fourth flash also cannot be detected. Thresholds of a number of normal people have been determined, including spouses and accompanying persons in a glaucoma clinic, and the normal colour contrast threshold has been found to be $4.5 \%$, with a range from 3 to $7 \%$ : similar thresholds are found for colours which lie along protan, deutan, and tritan axes. In cases of eye disease a loss of colour contrast sensitivity along a single one of these axes can frequently be observed. This is convenient, since a normal result (achieved along the protan axis, for example) indicates that psychological variables are not affecting the determination of threshold. Therefore a loss in a different axis, even though the threshold is only marginally above the upper limit of normal, is an indication of disease. Further details are given elsewhere. ${ }^{10-12}$

\section{SUBJECTS}

Consultant surgeons and residents of the Retinal Diagnostic Department of Moorfields Eye Hospital who are involved in the treatment of large numbers of diabetic patients were tested before and after they had finished a session (nominally 3.5 hours) of treatment by standard panphotocoagulation. Usually these were morning sessions, so measurements were made before 9 am and in the early afternoon. As controls we used members of the Medical Illustration Department, because these persons do fundus photography and fluorescence angiography on the same patient population. They use fundus cameras, slitlamps and ophthalmoscopes, so their work involves the use of similar viewing devices, during which the operator sees bright flashes from the sources used to illuminate the patient's retina. Thus the work of the control group was matched as closely as possible to that of the laser users. Table 1 gives the ages of the 
Table 1 Ages and experience of subjects tested

\begin{tabular}{|c|c|c|c|c|}
\hline & \multicolumn{2}{|c|}{ Laser operators } & \multicolumn{2}{|c|}{ Medical photographers } \\
\hline & Age & $\begin{array}{l}\text { Has used } \\
\text { equipment for } \\
\text { (years) }\end{array}$ & Age & $\begin{array}{l}\text { Has used } \\
\text { equipment for } \\
\text { (years) }\end{array}$ \\
\hline 1 & 34 & 1 & 40 & 20 \\
\hline 2 & 38 & 3 & 22 & 4 \\
\hline 3 & 33 & 1 & 22 & 5 \\
\hline 4 & 51 & 15 & 33 & 8 \\
\hline 5 & 36 & 4 & 58 & 32 \\
\hline 6 & 33 & 5 & 52 & 27 \\
\hline
\end{tabular}

Age (mean with SD): $37 \cdot 5(6 \cdot 9)$ $37 \cdot 8(15 \cdot 1)$

subjects, and the time for which they had been engaged in the intensive use of lasers or had used the fundus cameras on a daily basis. None of those subjects had ever experienced an incident in which a laser was used incorrectly or had used a laser in which there had been any optomechanical failure (but see below).

\section{LASERS}

A Lasertek $41 \mathrm{AK}$ and Coherent 900 are in use at Moorfields.

Both blue and green lines are employed in these lasers. We have also tested visiting ophthalmologists, and we have no reason to suppose that the model of laser used has any bearing on the results shown below. The light outputs of the Moorfields lasers are monitored by the makers and by the Laser Safety Officer. A radiometer (EE \& G Ltd) placed at the eyepiece of the binocular microscope recorded $40-90$ $\mu \mathrm{W} / \mathrm{cm}^{2}$.

\section{OPHTHALMIC TESTING}

All the persons tested had a corrected acuity of $6 / 6$ or better, and none had any ocular or systemic abnormality. All had recently been investigated with biomicroscopy. All had had ocular vision tests with HRR plates or the 100 -hue test, and no test result was abnormal.

\section{Results}

Table 2 shows the results which drew our attention to the phenomenon we report.

The test-retest results from a normal observer are shown for a period of five days. The subject was tested twice daily for all colour combinations, but only the results on the tritan axis are shown (the others are comparable). The thresholds (expressed as a percentage of the maximum colour contrast obtainable - see 'Methods') show that the variability of threshold was small in a trained observer. Since the
Table 2 Test-retest variability in two subjects, showing the diurnal variation in one following exposure to laser light. The measurements of colour contrast sensitivity were made along the tritan colour confusion line

\begin{tabular}{|c|c|c|}
\hline $\begin{array}{l}\text { Measurement } \\
\text { on day number }\end{array}$ & \multicolumn{2}{|c|}{$\begin{array}{l}\text { Contrast threshold (mean and } S D) \\
\text { (percent of maximum)* }\end{array}$} \\
\hline \multicolumn{3}{|l|}{ Non-user of laser } \\
\hline 1 & $4 \cdot 8(0 \cdot 2)$ & $5 \cdot 1(0 \cdot 2)$ \\
\hline 2 & $4.9(0.2)$ & $5 \cdot 2(0 \cdot 1)$ \\
\hline 3 & $4 \cdot 7(0 \cdot 1)$ & $5 \cdot 0(0 \cdot 2)$ \\
\hline 4 & $4 \cdot 7(0 \cdot 3)$ & $5 \cdot 0(0 \cdot 3)$ \\
\hline 5 & $4.9(0.2)$ & $5 \cdot 2(0 \cdot 2)$ \\
\hline Average of results & $4 \cdot 8(0 \cdot 2)$ & $5 \cdot 1(0 \cdot 2)$ \\
\hline \multicolumn{3}{|c|}{ Mean difference between am and pm thresholds $0 \cdot 3(0 \cdot 0)$} \\
\hline \multicolumn{3}{|l|}{ Laser operator } \\
\hline 1 & $6.4(0.2)$ & $8 \cdot 8(0 \cdot 2)$ \\
\hline 2 & $6 \cdot 2(0 \cdot 2)$ & $9 \cdot 1(0.3)$ \\
\hline 3 & $6 \cdot 5(0 \cdot 3)$ & $9.9(0.4)$ \\
\hline Average of results & $6 \cdot 4(0 \cdot 2)$ & $9 \cdot 3(0 \cdot 3)$ \\
\hline
\end{tabular}

*Average normal result=4·5. Maximum normal result=7·0.

minimum increment of colour contrast is $1 \%$, the subject evidently always responds when the colour contrast has been incremented either 4,5 , or 6 times from the zero condition. The slight but nonsignificant increase in threshold determined in the afternoon implies that the probability that he responded to the 6 th increment was slightly higher at the end of the session.

The results for a laser user are shown below. He was tested only in the tritan axis. Note that the mean level in the morning was higher for this subject, but the thresholds were within normal limits. The reproducibility of the threshold in the morning before the laser was used in also impressive. The three readings were obtained on three separate occasions, spanning three months. Following the use of the laser the threshold was higher and above the highest value (7.0) found in other normal subjects, but again thresholds on three afternoons were very similar. The difference between morning and afternoon sessions is significant, but not highly $(t=10 \cdot 0, \mathrm{n}=3)$, and it is possible that this subject had an unusual circadian change in colour contrast threshold.

Therefore additional observations were made with a group of six users of lasers, matched with other hospital employees, whose work consisted of repeated funduscopy and the use of bright lights (Table 1). The results are shown in Table 3. In these subjects only one set of measurements was made, but thresholds were determined along protan, deutan, and tritan colour-confusion lines. As will be seen, the first two measurements provide a useful additional control.

Inspection of Table 3 shows that before the session 
Table 3 Thresholds before and after a working sessions (mean and SD)

\begin{tabular}{|c|c|c|c|c|c|c|c|c|c|c|c|}
\hline \multicolumn{4}{|l|}{ Protan } & \multicolumn{4}{|l|}{ Deutan } & \multicolumn{4}{|l|}{ Tritan } \\
\hline \multicolumn{2}{|c|}{ Laser users } & \multicolumn{2}{|l|}{ Others } & \multicolumn{2}{|c|}{ Laser users } & \multicolumn{2}{|l|}{ Others } & \multicolumn{2}{|l|}{ Laser users } & \multicolumn{2}{|l|}{ Others } \\
\hline $\begin{array}{l}\text { Before } \\
\text { session }\end{array}$ & $\begin{array}{l}\text { After } \\
\text { session }\end{array}$ & $\begin{array}{l}\text { Before } \\
\text { session }\end{array}$ & $\begin{array}{l}\text { After } \\
\text { session }\end{array}$ & $\begin{array}{l}\text { Before } \\
\text { session }\end{array}$ & $\begin{array}{l}\text { After } \\
\text { session }\end{array}$ & $\begin{array}{l}\text { Before } \\
\text { session }\end{array}$ & $\begin{array}{l}\text { After } \\
\text { session }\end{array}$ & $\begin{array}{l}\text { Before } \\
\text { session }\end{array}$ & $\begin{array}{l}\text { After } \\
\text { session }\end{array}$ & $\begin{array}{l}\text { Before } \\
\text { session }\end{array}$ & $\begin{array}{l}\text { After } \\
\text { session }\end{array}$ \\
\hline $\begin{array}{l}5 \cdot 6(0.8) \\
7 \cdot 2(0.3) \\
6 \cdot 2(0.2) \\
8 \cdot 3(0.4) \\
8 \cdot 1(0.4) \\
5 \cdot 5(0.4)\end{array}$ & $\begin{array}{l}5 \cdot 5(0 \cdot 2) \\
9 \cdot 0(0 \cdot 1) \\
6 \cdot 2(0 \cdot 2) \\
9 \cdot 8(0 \cdot 4) \\
8 \cdot 2(0 \cdot 6) \\
5 \cdot 9(0 \cdot 3)\end{array}$ & $\begin{array}{l}4 \cdot 5(0 \cdot 5) \\
5 \cdot 4(0 \cdot 3) \\
5 \cdot 4(0 \cdot 3) \\
4 \cdot 5(0 \cdot 3) \\
5 \cdot 4(0 \cdot 4) \\
6 \cdot 1(0 \cdot 3)\end{array}$ & $\begin{array}{l}4 \cdot 8(0 \cdot 5) \\
5 \cdot 7(0 \cdot 5) \\
5 \cdot 7(0 \cdot 3) \\
4 \cdot 5(0 \cdot 3) \\
5 \cdot 5(0.4) \\
6 \cdot 3(0.4)\end{array}$ & $\begin{array}{l}5 \cdot 3(0 \cdot 3) \\
7 \cdot 7(0 \cdot 4) \\
6 \cdot 0(0 \cdot 2) \\
8 \cdot 8(0 \cdot 8) \\
8 \cdot 3(0 \cdot 4) \\
6 \cdot 1(0 \cdot 3)\end{array}$ & $\begin{array}{r}5 \cdot 3(0 \cdot 1) \\
9 \cdot 2(0 \cdot 3) \\
6 \cdot 9(0 \cdot 2) \\
10 \cdot 2(0 \cdot 7) \\
10 \cdot 3(0 \cdot 7) \\
6 \cdot 0(0 \cdot 1)\end{array}$ & $\begin{array}{l}4 \cdot 8(0 \cdot 3) \\
5 \cdot 3(0 \cdot 4) \\
5 \cdot 2(0 \cdot 4) \\
4 \cdot 6(0 \cdot 2) \\
5 \cdot 2(0 \cdot 3) \\
6: 2(0 \cdot 2)\end{array}$ & $\begin{array}{l}4.9(0.3) \\
5.9(0.5) \\
5.6(0.5) \\
4.9(0.1) \\
5.6(0.4) \\
6.4(0.2)\end{array}$ & $\begin{array}{r}5.0(0.3) \\
8 \cdot 5(0.3) \\
6.4(0.2) \\
12.2(0.9) \\
10 \cdot 0(0.5) \\
6 \cdot 1(0.2)\end{array}$ & $\begin{array}{r}6 \cdot 3(0 \cdot 6) \\
13 \cdot 5(1 \cdot 3) \\
8 \cdot 8(0 \cdot 2) \\
12 \cdot 8(0 \cdot 6) \\
13.0(0 \cdot 8) \\
6.9(0 \cdot 1)\end{array}$ & $\begin{array}{l}6 \cdot 5(0 \cdot 5) \\
6 \cdot 6(0 \cdot 4) \\
6 \cdot 4(0 \cdot 3) \\
4 \cdot 7(0 \cdot 2) \\
5 \cdot 5(0 \cdot 3) \\
6 \cdot 3(0 \cdot 4)\end{array}$ & $\begin{array}{l}6 \cdot 7(0 \cdot 4) \\
6 \cdot 7(0 \cdot 4) \\
6 \cdot 8(0 \cdot 1) \\
4 \cdot 8(0 \cdot 1) \\
5 \cdot 7(0 \cdot 4) \\
6 \cdot 6(0 \cdot 3)\end{array}$ \\
\hline $\begin{array}{l}\text { Mean val } \\
6 \cdot 8(0 \cdot 4) \\
\text { Mean of } \\
\text { 'after' ses } \\
0\end{array}$ & $\begin{array}{l}\text { es of the gr } \\
7.4(0.3) \\
\text { ifferences b } \\
\text { ion test } \\
33(0.81)\end{array}$ & $\begin{array}{l}\text { ups } \\
5 \cdot 2(0 \cdot 4) \\
\text { tween 'bef }\end{array}$ & $\begin{array}{l}5 \cdot 4(0 \cdot 4) \\
\text { re' and } \\
1(0 \cdot 23)\end{array}$ & $\begin{array}{l}\text { Mean val } \\
7 \cdot 0(0 \cdot 4) \\
\text { Mean of } \\
\text { 'after' ses } \\
0\end{array}$ & $\begin{array}{l}\text { es of the gro } \\
8.0(0 \cdot 4) \\
\text { fferences be } \\
\text { ion test } \\
5(0 \cdot 85)\end{array}$ & $\begin{array}{l}\text { ups } \\
\begin{array}{l}5 \cdot 2(0 \cdot 3) \\
\text { tween "bef }\end{array} \\
0 .\end{array}$ & $\begin{array}{l}5 \cdot 6(0 \cdot 3) \\
\text { re' and } \\
3(0 \cdot 17)\end{array}$ & $\begin{array}{r}\text { Mean valu } \\
8.0(0.4) \\
\text { Mean of d } \\
\text { 'after' sess } \\
2 .\end{array}$ & $\begin{array}{l}\text { les of the gro } \\
10 \cdot 2(0 \cdot 6) \\
\text { ifferences be } \\
\text { ion test } \\
18(1 \cdot 66)\end{array}$ & $\begin{array}{l}\text { ups } \\
6 \cdot 0(0 \cdot 4) \\
\text { tween 'bef }\end{array}$ & $\begin{array}{l}6 \cdot 2(0 \cdot 3) \\
\text { re' and } \\
22(0 \cdot 17)\end{array}$ \\
\hline
\end{tabular}

Significance of statistics

\begin{tabular}{|c|c|c|c|}
\hline t Test between & Protan & Deutan & Tritan \\
\hline $\begin{array}{l}\text { Laser user/non-laser user } \\
\text { Before/after session (laser user) } \\
\text { Before/after session (non-laser user) }\end{array}$ & $\begin{array}{l}p=0.02 \\
\text { NS } \\
\text { NS }\end{array}$ & $\begin{array}{l}\mathrm{p}<0.01 \\
\text { NS } \\
\text { NS }\end{array}$ & $\begin{array}{l}\mathrm{p}<0.001 \\
0.02<\mathrm{p}<0.05 \\
\mathrm{NS}\end{array}$ \\
\hline
\end{tabular}

the non-users of laser had values (mean $5 \cdot 2 \%$ ) similar to those previously reported. The results along protan and deutan colour confusion lines given by the

Fig. 1 The relationship between colour contrast thresholds (ordinate) and use of the argon laser (abscissa). The results from the right eye are given by circles and the left eye by triangles. Colour contrast thresholds are expressed as a percentage of the maximum colour separation possible. The upper limit of normal =7 for both protan colour confusion line measurements (open symbols) and for tritan measurements (filled symbols). The subject used his left eye to view the right eyepiece of the binocular, so that it received 'flashbacks', while with the right eye he could see (round the side of the biomicroscope) the reflections from the photocoagulating beam. Groups of 100 laser burns were given at the arrows. It is the left eye in which the threshold elevations occur. Note that the effect of the laser is more pronounced for the tritan (blue-yellow) colours, and the effect takes 1-2 hours to reverse. Measurements taken on the following day show the result is not due a circadian phenomenon. laser users were slightly higher than the corresponding values for non-users of laser. Although the mean result is just within normal limits, subjects 4 and 5 had values that initially slightly exceeded any of those found in the normal population. The mean tritan value of the laser users was initially higher than the upper limit of normal, and some of the individual

\section{Colour Contrast Thresholds}

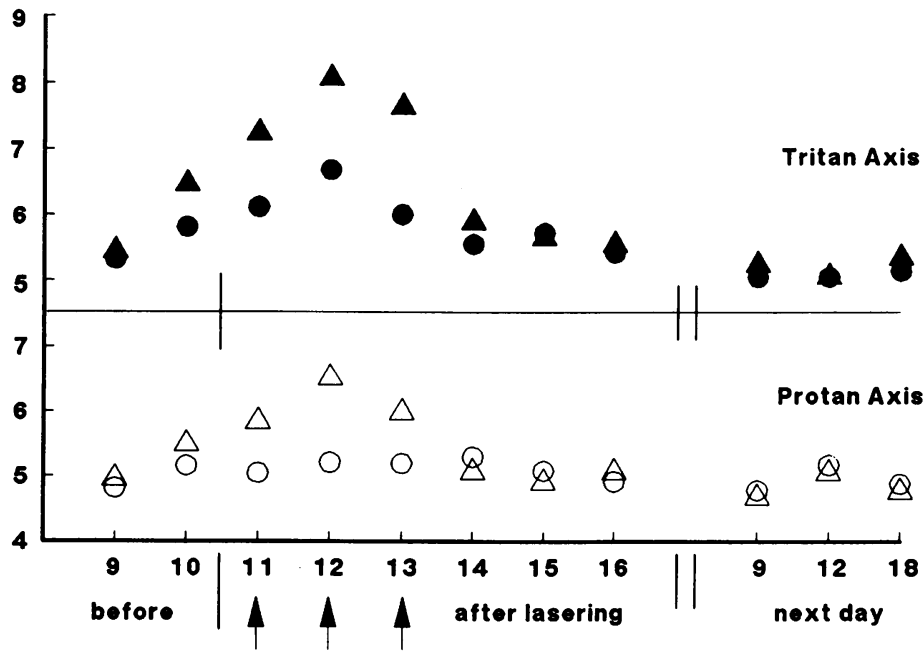

Time of Day 
results were very high indeed. While it is statistically very probable that the laser users differed from the remainder in respect of the initial protan and deutan results, it is evident that there was an additional loss, confined to the tritan axis only, which cannot be explained on the basis that the test was not performed adequately by the surgeons: for the protan and deutan results were not nearly so high. There appears to be a real, selective loss of blue-yellow colour contrast which cannot be explained by any systematic difference between the surgeon and control groups.

After the session results given by the non-users of laser have changed very little. Thus, if there is a circadian effect or an effect of fatigue, it is reasonable to assume that it is no more than $0.2-0.3$ percentage units. The protan and deutan results of the laser users showed increases which were larger but not grossly different from those of the controls -0.6 and 0.95 for the two axes. For the tritan results the increase was much greater $-2 \cdot 2 \%$. The person with the highest initial threshold showed the smallest increase, and therefore the mean of the increases of threshold (mean of the individual differences between the findings before and after the session) has a fairly large variance. It appears likely that during the session laser users experienced further losses in blue-yellow contrast sensitivity. In this context it is understandable that the person with the severest initial loss experienced the least additional loss.

If the results shown in the tables indicate that the use of the laser causes a change in threshold, the change ought to be progressive with continued use. For this reason we simulated the clinical use of the laser by placing a plane surface in the place of the eye and viewing it through one of the standard lenses with the biomicroscope. In one case a dark blue piece of card was used and in another a matte black card. In both cases the light reflected from the surfaces was less than from the normal fundus. The subject's colour vision was tested in the usual way, and then he made a series of 100 burns on the card as quickly as possible $(0.4 \mathrm{w}, 0.1 \mathrm{~s}, 500 \mu \mathrm{m}$ spot size $)$, and colour vision was immediately retested. In one experiment (on KG, see Fig. 1) the subject used his left eye to view the card through the right eyepiece of the binocular: thus it was exposed to all the 'flashbacks', but during the photocoagulating pulses no argon light entered his eye. The right eye on the other hand received no flashbacks but during the photocoagulating pulses saw some fraction of the intense argon light reflected from the card, the contact lens, and the subject's own hand.

It can be seen from Fig. 1 that colour contrast threshold along a protan colour-confusion line may change slightly as a result of the use of the laser, but only in the eye which receives the flashbacks. Similar results were obtained (but not illustrated in Fig. 1) for deutan colours. For the tritan (yellow-blue) grating, using the laser caused a larger change in threshold, which rose above the upper limit of normal in the eye which viewed the flashbacks. Smaller changes occurred in the fellow eye. Colour thresholds remained elevated for over 2 hours. Further measurements were taken the following day. There was no hint of any circadian rise of threshold toward midday.

This experiment was partially repeated on another observer, who held the contact lens centred in the optic pathway, so that its front plano surface was (as near as possible) normal to the optical pathway. This increased the frequency of flashbacks. After a period of 100 burns the subject's threshold rose to above normal, and after 300 , delivered as fast as the laser allowed, it more than doubled. The subject was aware that colour contrast threshold in his foveal region had risen above the level in the surrounding peripheral retina, so he had a relative blue-yellow scotoma, and that the major source of light was the flashbacks. He declined to continue the experiment.

\section{ADDITIONAL OBSERVATIONS}

We have measured colour contrast sensitivity after light-adapting the eye with bright photographic flashes that bleach most of the rhodopsin in the retina. These are used routinely to achieve a high level of light adaptation prior to measuring dark adaptation. They do not cause a loss of colour contrast sensitivity lasting for long enough to show on our test. We have tested one ophthalmologist who used an argon laser in which the protecting filter failed to cover completely the viewing path when the coagulating beam was employed. As a result the doctor experienced an after-image of some days' duration. A year after this incident colour contrast thresholds were normal and equal in the two eyes for all colour confusion lines. There was no tritan elevation. We have tested several visiting ophthalmologists from two centres on the continent. In two cases of persons over 40 years of age, one from Italy and one from Denmark, who had used argon lasers on a daily basis for several years, tritan colour contrast thresholds were elevated (as in Table 3), though the doctors had not used the laser for several weeks.

\section{Discussion}

Colour contrast sensitivity measurements are a new way of assessing colour vision. The test-retest reliability of our system, both in general and in the results shown above, is such that the elevations we see in the surgeons tested cannot be ascribed to normal variation. Again, the elevations are much 
more marked for one particular colour confusion line, as is often the case in acquired disease, and therefore cannot be considered as part of the population variation. We have also conducted experiments which show that the threshold elevation is progressive, and threshold varies with the length of time the laser is used. We have shown that circadian changes cannot be implicated and that the losses seen are not found in a group of hospital workers who use the same types of equipment (and which deliver intense flashes to the patients' eyes) but who do not use lasers. Therefore we can be sure that general fatigue cannot explain our results. It appears that there are losses of colour contrast sensitivity associated with the use of lasers. Although the series is small, we believe that the loss is greatest in the persons who have used the lasers longest.

If the loss is associated with the use of lasers, is it caused by laser light or by some undefined factor? The results shown in Fig. 1 suggest very strongly that the flashbacks cause the threshold elevation, and a body of evidence indicates that blue light is an especial hazard. Our interpretation of the results is that in argon laser users so much blue light enters the eye that blue cones are selectively affected and colour contrast threshold rises, and recovers slowly. As the years go by, the recovery slows down, till a semipermanent elevation of threshold results.

Hawerth and Sperling ${ }^{15}$ have shown that blue light causes irreversible colour vision defects in monkeys. Marshall ${ }^{1617}$ has calculated that the intensity of light entering the laser users' eyes is approximately equal to that used by Hawerth and Sperling. After exposure to lesser intensities of blue light there is a transient increase in threshold, and Zrenner ${ }^{18}$ has used this fact to develop a clinical test. Our results are not necessarily in conflict with those of Sliney and Mainster, ${ }^{7}$ who have recently calculated that blue argon light should not be damaging to the laser user's eye. Estimates of damage are derived from assessment of histological lesions in monkeys. There is no evidence that any of our subjects had such lesions, and indeed all tests of vision and colour vision (except our new test of colour contrast sensitivity) have failed to show any visual defect at all.

However, our measurements suggest that repeated exposure to levels of blue argon light may slowly cause small losses of colour contrast sensitivity along an appropriate colour dimension, which may be irreversible or slow to recover. There is no reason why such losses should be associated with other visual impairment: the blue cones are thought to contribute little to visual acuity or to the detection of luminance. However, if further work confirms that even minor changes occur in ophthalmologists' eyes, it is likely that there would be pressure for the redesign of medical laser systems.

We thank the consultants and resident staff of the Retinal Diagnostic Department and Medical Illustration staff for participating: and $\mathrm{Mr}$ C R Hogg, who provided technical support; the Laser Safety Officer of Moorfields Eye Hospital (Professor J Marshall) for providing evidence about the calibration and maintenance of lasers. KG held a British Council Fellowship. The work was supported by a Wellcome Trust grant to GBA.

\section{References}

1 Irvine AR, Norton EWD. Photocoagulation for diabetic retinopathy. Am J Ophthalmol 1971; 71: 437-45.

2 Diabetic Retinopathy Study Research Group. Preliminary report on effects of photocoagulation therapy. Am J Ophthalmol 1976; 81: 383-96.

3 Diabetic Retinopathy Study Research Group. Photocoagulation treatment of proliferative diabetic retinopathy: second report of diabetic retinopathy study findings. Am J Ophthalmol 1978; 85: 82-106.

4 Sokol S, Moskowitz A, Skarf B, Evans R, Molitch M, Senior B. Contrast sensitivity in diabetics with and without background retinopathy. Arch Ophthalmol 1985; 103: 51-4.

5 Higgins KE, Meyers SM, Jaffe MJ, Roy MS, de Monasterio FM. Temporary loss of foveal contrast sensitivity associated with panretinal photocoagulation. Arch Ophthalmol 1986; 104: 9971003.

6 Gündüz K, Arden GB, Perry S. A new test of colour vision using TV and computergraphics: results in some common acquired eye diseases. In: Kulikowski J, eds. Seeing contour and colour in press.

7 Sliney DH, Mainster MA. Potential laser hazards to the clinician during photocoagulation. Am J Ophthalmol 1987; 103: 758-60.

8 Sliney DH, Wolbarsht ML. Safety with lasers and other optical sources. New York: Plenum, 1980.

9 Arden GB. Visual loss in patients with normal visual acuity. Trans Ophthalmol Soc UK 1978; 98: 219-31.

10 Arden GB, Gündüz K, Perry S. Colour vision testing with a computergraphics system. Clin Vis Sci 1988; 2: 303-20.

11 Arden GB, Gündüz K, Perry S. Colour vision testing with a computergraphics system: preliminary results. Doc Ophthalmol 1988; 69: 167-74.

12 Gündüz K, Arden GB, Perry S, Weinstein GW, Hitchings RA. Colour vision defects in ocular hypertension and glaucoma quantified with a computer driven colour TV system. Arch Ophthalmol 1988; 106: 929-35.

13 Arden GB. Testing contrast sensitivity in clinical practice. Clin Vis Sci 1988; 2: 213-24.

14 Foster DH, Scase MO, Taylor SP. Anomalous loss in bluegreen hue discrimination in very brief monochromatic stimuli presented to the normal human eye. J Physiol (Lond) 1986; 381: $64 \mathrm{P}$.

15 Hawerth RS, Sperling HG. Prolonged colour blindness induced by intense spectral lights in rhesus monkey. Science 1971; 114: 520.

16 Marshall J. Light damage and the practice of ophthalmology. In: Rosen MS, Haining WM, Arnott EJ, eds. Intraocular lens implantation. St Louis: Mosby, 1984: 183-207.

17 Marshall J. Light damage and ageing in the human macula. Res Clin Forums 1985; 7: 27-43.

18 Zrenner E. Electrophysiological characteristics of the blue sensitive mechanism: test or a model of cone interaction under physiological and pathological conditions. In: Verriest G, ed. Doc Ophthalmol Proc Ser 1982; 33: 103-25.

Accepted for publication 28 April 1988. 